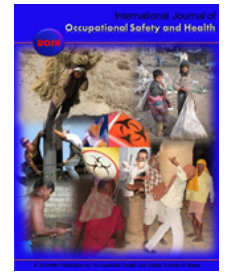

Available Online at http://nepjol.info/index.php/IJOSH

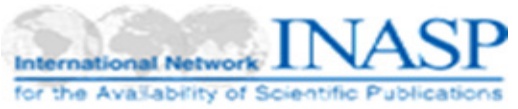

International Journal of Occupational Safety and Health, Vol 1 (2011) 7 - 13

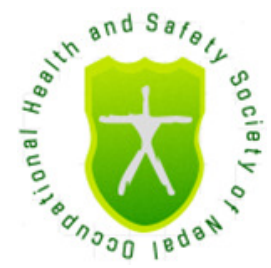

Original Article

\title{
When the exchange rate makes a difference: Noise Monitoring of Traffic Police in the Kathmandu Valley, Nepal William S. Carter, ${ }^{1}$ Rupesh Rauniyar ${ }^{2}$ \\ ${ }^{1}$ The University of Findlay, Findlay, OH 45840, ${ }^{2}$ Kathmandu University, Dhulikel, Kaure, Nepal
}

\begin{abstract}
:
This study demonstrates that when measuring wide swings in noise over short time periods, Time Weighted Average (TWA) calculated results may vary significantly depending upon the exchange rate used. The $3 \mathrm{dBA}$ exchange rate, the ACGIH recommended criteria, results in statistically significant higher values than the $5 \mathrm{dBA}$ exchange rate recommended by OSHA, when noise levels vary from $70 \mathrm{dBA}$ to $120 \mathrm{dBA}$ while measurements are taken.

A field study of noise levels among the traffic police in the Kathmandu Valley was conducted in the spring of 2009. Sampling was done at 5 high density traffic areas on and inside the Ring Road (valley perimeter road). To collect sufficient data, hourly integrated personal and area samples were simultaneously taken with a dosimeter to identify hazardous noise areas and work locations that should be included in a hearing conservation program.

This study demonstrates the importance of taking several integrated samples over short periods of time when average noise levels vary. This study likewise illustrates that area samples may not accurately reflect personal exposure, particularly when there are large variations in temporal and areal measurements. This study is the first to collect personal noise data associated with traffic noise in Nepal.
\end{abstract}

Key Words: personal noise monitoring, Integrated Sampling, 3 dBA exchange rate, traffic noise, Nepal

\section{Introduction}

United States and international standards for occupational noise level exposure have differed for several years. The International Organization of Standards (ISO) recommends a threshold limit of $80 \mathrm{dBA}$ and exchange rate of $3 \mathrm{dBA}$. The United States Occupational Safety and Health Administration (OSHA) established a threshold limit of $80 \mathrm{dBA}$ and exchange rate of $5 \mathrm{dBA}$. The threshold limit is the minimum noise level measured. The exchange rate is the quantity by which the sound level may increase if the exposure time is reduced by one half. This discrepancy results in inconsistency when reporting noise levels.

Corresponding Author: Professor William S. Carter

Email: carter@findlay.edu

(c) 2011 OHSSN All rights reserved.
In 1994 the American Industrial Hygiene Association (AIHA) and since then others, including Prince et.al. (1997), Daniel et.al. (2007) and Suter (2009), recommended an exchange rate of 3 dBA and an 8 hour criterion level of 85 dBA. In 1998, the National Institute of Occupational Safety and Health (NIOSH, 1998) recommended that for occupational noise exposure 1.) the exchange rate should be $3 \mathrm{dBA}$ rather than $5 \mathrm{dBA}$ and 2.) the maximum exposure should be $85 \mathrm{dBA}$ for 8 hours, consistent with international standards. These recommendations were based on a review of risk assessments conducted by the ISO, the Environmental Protection Agency (EPA), and previous NIOSH data. Continuous noise level exposure for 8 hours was the baseline for determining hearing loss. In the 1998 report, NIOSH encouraged ongoing efforts to develop monitoring strategies applicable to various occupational conditions. A 2001 World Health Organization (WHO, 2001) report states "An occupational 
exposure limit of $85 \mathrm{dBA}$ for 8 hours [and at a $3 \mathrm{dBA}$ exchange rate] should protect most people against a permanent hearing impairment induced by noise after 40 years of occupational exposure." Yet in 2007 Dobie claims there is no evidence preferring a $3 \mathrm{dBA}$ exchange rate over the current $5 \mathrm{dBA}$ in the OSHA Hearing Conservation standard. This paper describes conditions under which the $3 \mathrm{dBA}$ exchange rate is preferable and should be employed in such calculations.

A worker's exposure may vary based on his/her activity surrounding activities. Further, the worker may not be aware of significant noise variations. The findings in this paper demonstrate that when noise levels repeatedly range above and below the threshold limit, there can be a significant difference in the calculated Time Weighted Average (TWA) noise level when using the $3 \mathrm{dBA}$ versus the $5 \mathrm{dBA}$ exchange rate.

Traffic noise as an environmental pollutant and workplace hazard has unique characteristics that require specialized approaches to sample and characterize the hazard. In 1990 the ISO stated noise produced by motorized transportation can adversely impact the health of both the general public and workers associated with traffic management. Joshi et. al. (2003) used surveys to identify the effect of traffic noise on hearing loss in Nepal, with particular emphasis on the Kathmandu Valley in Nepal. Traffic police are often in close proximity to traffic and therefore are exposed to relatively high levels of noise. Motor vehicles were first introduced into the Kathmandu Valley in 1958. Since then the number of motorcycles, automobiles, buses, and trucks has increased rapidly. Sprawling urbanization, an inefficient public transportation system, inefficient operation of vehicles, and narrow roads and streets greatly increase the hazard of noise pollution. There are few electrical traffic control devices, so traffic police are deployed to control traffic in busy intersections.

Kathmandu, located at Latitude $27^{\circ} 40^{\prime} 0 \mathrm{~N}$ and Longitude $85^{\circ}$ 20 ' $60 \mathrm{E}$, is the capital and largest metropolitan area of Nepal. The city sits in a valley at an elevation of approximately 1400 meters surrounded by mountains, with two major rivers transecting the city. In 2009 the official population estimate for Kathmandu Valley was approximately 2,000,000 with a density of 2305 person per square kilometer. Migration of rural workers seeking employment often swells the urban population. Despite a complex terrain with several traffic restrictions, Kathmandu has the most advanced infrastructure among urban areas in Nepal.

Earlier studies by Manandhar et. al. (1987) measured area environmental noise levels in some central city areas in the Kathmandu Valley. Khanal and Acharya (1994) further documented noise levels in all parts of the city. These studies employed environmental area monitoring and so did not reflect personal exposure of workers. The goal of this study was to investigate the personal exposure of traffic police in the Kathmandu Valley, and make recommendations regarding noise control to improve worker health and safety.

\section{Methods}

To establish criteria for collecting data, we conducted an initial survey at selected traffic locations in Kathmandu, using a Simpson 886-Type 2 Sound Level Meter (SLM) with a model 898 Octave Band Filter (Simpson Electric, Lac du Flambeau, WI). The A weighting scale with slow response function was employed for frequency measurements. The Octave Band instrument was calibrated at 10 Octave Bands within $2 \mathrm{dBA}$ of the two point calibration of $94 \mathrm{dBA}$ and $114 \mathrm{dBA}$. These measurements demonstrated that most dominant traffic frequencies fall within the $2 \mathrm{KHz}$ and $4 \mathrm{Kz}$ range. We confirmed this by measuring a representative source, a commonly used Bajaj Avenger motorcycle, observing noise levels of $104 \mathrm{dBA}$ at $2 \mathrm{KHz}$ and 96 $\mathrm{dBA}$ at $4 \mathrm{KHz}$ at a distance of 3.6 meters and height of 1 meter.

To select monitoring sites, we conducted initial evaluations of traffic patterns at several intersections along the Ring Road, the major road which circles Kathmandu, and at center city intersections. With the Kathmandu Metropolitan Traffic Police Department (KMTPD) we selected five intersections as representative of traffic patterns in the valley. This included three intersections in Kathmandu proper, Bhotahity, Thapathali, and Jawalakhel, and two on the Ring Road, Koteshwor and Narayan Gobal (Figure 1). The KMTPD previously had identified peak traffic hours in the Kathmandu Valley to be from 8:30 to 11:00 AM and 3:30 PM to 7:00 PM. At the five selected sites we collected hourly integrated samples between 8:30 AM and 6:30 PM.

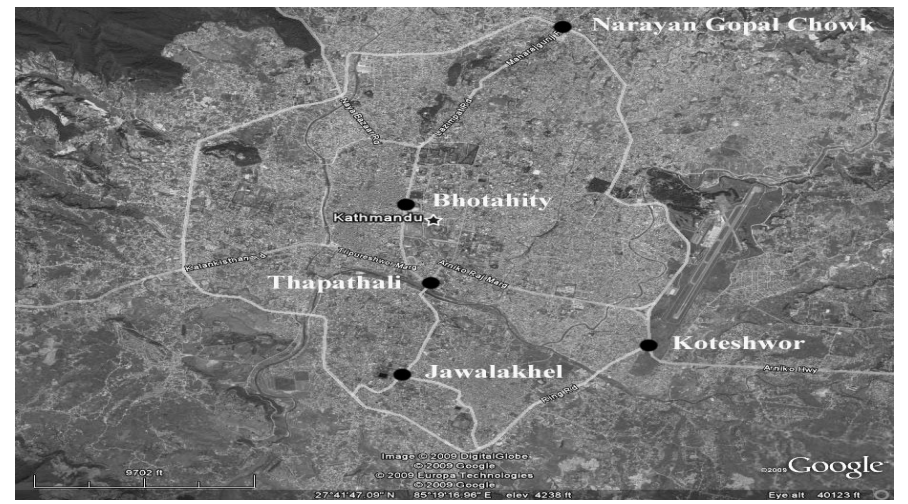

Figure 1. Map of Kathmandu Valley with sampling intersections 


\section{Integrated Q-300 Noise Dosimeter Sampling:}

The goal of this study was to determine the effect of vehicular noise on working traffic police. We therefore developed an integrated sampling strategy to conduct both (1) time averaged personal samples of traffic police and (2) time averaged area samples, employing a Quest Model Q-300 noise dosimeter (Quest Technologies, Oconomowoc, WI). The dosimeter was checked for accuracy prior to each use with a standard $114 \mathrm{dBA}$ calibration source. Measurements were taken every minute and the results were integrated hourly. All data was analysed using the Quest Suite Professional Computer Program (QSPCP). Three channels of the dosimeter were set as described in Table I.

Table I Settings of the Quest-300 Dosimeter

\begin{tabular}{cccccc}
\hline $\begin{array}{c}\text { Typical } \\
\text { Setups }\end{array}$ & $\begin{array}{c}\text { Thresh- } \\
\text { old }\end{array}$ & $\begin{array}{c}\text { Exchange } \\
\text { Rate }\end{array}$ & Criteron & Weighting & $\begin{array}{c}\text { Re- } \\
\text { sponse }\end{array}$ \\
\hline $\begin{array}{c}\text { OSHA } \\
\text { Noise }\end{array}$ & $90 \mathrm{~dB}$ & $5 \mathrm{~dB}$ & $90 \mathrm{~dB}$ & $\mathrm{~A}$ & Slow \\
$\begin{array}{c}\text { Compli- } \\
\text { ance }\end{array}$ & & & & & \\
$\begin{array}{c}\text { OSHA } \\
\text { Hearing } \\
\text { Conser- } \\
\text { vation }\end{array}$ & $80 \mathrm{~dB}$ & $5 \mathrm{~dB}$ & $90 \mathrm{~dB}$ & $\mathrm{~A}$ & Slow \\
$\begin{array}{c}\text { ACGIH } \\
\text { Criteria }\end{array}$ & $80 \mathrm{~dB}$ & $3 \mathrm{~dB}$ & $85 \mathrm{~dB}$ & $\mathrm{~A}$ & Slow \\
\hline
\end{tabular}

At all sites measured, noise levels showed swings from approximately $70 \mathrm{dBA}$ to greater than $90 \mathrm{dBA}$ in less than 30 seconds. Only noise exceeding $90 \mathrm{dBA}$ with an exchange rate of $5 \mathrm{dBA}$ was collected in the first channel, called OSHANC. This allowed us to observe during the data collection period variations in louder noise sources. All noise above a threshold of $80 \mathrm{dBA}$ was collected in channels two and three. While some traffic police work more than an 8 hour day, we used projected 8-hour TWA calculations. Results reported in Table 2 compare the ACGIH TWA calculations with an exchange rate of $3 \mathrm{dBA}$ to the OSHA Hearing Conservation (OSHAHC) values with an exchange rate of 5 dBA.

During the monitoring periods we conducted a count of light and heavy vehicles for 5 minutes each hour. Light vehicles include motorcycle, van, car, pick-up truck, microbus, Tuk-Tuk(threewheeled electric passenger vehicle), and tractor. Heavy vehicles include bus, truck, construction vehicles, and fire vehicles.

Personal monitoring was conducted at three intersections. The microphone was clipped to the collar of a traffic police person, representative of the exposure group, and monitored continuously for up to 8 hours. Traffic police roam the intersection to manage traffic movement and are at varying risks for noise exposure since the distance from a source may vary. The data was logged in approximately one hour integrated intervals allowing for both peak hours and off-peak hours measurements. Sampling was set on three channels of the dosimeter as described previously. Prior to personal monitoring approval was obtained from the Nepal Health Research Council and the Institutional Review Board at The University of Findlay.

Area monitoring was conducted at five intersections. The dosimeter was placed on a traffic kiosk in the middle of the crossroads and at various traffic points to determine the range of noise in the intersection. In all cases it was placed at a height of one meter. At the end of each hour the area monitor was moved to a different traffic point. Data was logged at each point to obtain a pattern of noise throughout the intersection.

\section{Results}

This paper employs the $3 \mathrm{dBA}$ exchange rate, recommended by $\mathrm{ACGIH}$, and the $5 \mathrm{dBA}$, recommended by OSHA, to calculate the TWA noise level exposures of traffic police at five intersections in the Kathmandu valley. The results demonstrate that when noise levels vary from below the threshold limit to well above the threshold limit there is a significant difference between the Time Weighted Average (TWA) when using these exchange rates.

\section{Personal Monitoring:}

Three intersections for personal monitoring were chosen because of differences in traffic flow and surrounding conditions. Table 2 summarizes the results.

Koteshwor is an open area on the Ring Road at the junction of three routes where noise reflection is relatively low. Average vehicle density was 40 light vehicles and 9.2 heavy vehicles per minute evenly distributed over the day with moderate increase between 2:30 and 6:30 PM. We collected personal noise data for 10 hours, from 8:30 AM to 6:30 PM.

Narayan Gopal, also on the Ring Road, is at a major crossroad of converging roads surrounded by several tall buildings. Noise reflection is relatively high. Average vehicle density was 72.4 light vehicles and 8.5 heavy vehicles per minute evenly distributed over the day with a decreasing pattern in the evening. 
Table II Personal Monitoring

\begin{tabular}{|c|c|c|c|c|c|}
\hline $\begin{array}{l}\text { Traffic Chowk } \\
\text { Intersection }\end{array}$ & Sampling Time & $\begin{array}{l}\text { TWA ACGIH } \\
\text { (dBA) }\end{array}$ & TWA OSHA (dBA) & $\begin{array}{c}\% \text { time exceeding } \\
90 \text { DBA }\end{array}$ & $\begin{array}{c}\% \text { time between } 80 \\
\text { and } 90 \mathrm{dBA}\end{array}$ \\
\hline \multirow[t]{11}{*}{ Koteshwor } & 8:38-9:39 AM & 82.2 & 78.3 & & \\
\hline & $9: 39-10: 39$ AM & 83.9 & 79.4 & & \\
\hline & 10:39-11:35 AM & 97.1 & 91.7 & & \\
\hline & $11: 35$ AM- 12:35 PM & 97.1 & 90.2 & & \\
\hline & $12: 35-1: 38$ PM & 94.6 & 86.7 & & \\
\hline & 1:38- 2:36 PM & 94.0 & 87.5 & & \\
\hline & 2:36-3:25 PM & 87.1 & 80.1 & & \\
\hline & 3:36-4:37 PM & 97.5 & 91.0 & & \\
\hline & 4:37-5:39 PM & 94.6 & 87.4 & & \\
\hline & 5:39-6:36 PM & 96.6 & 87.7 & & \\
\hline & Total Day (Lavg) & 94.8 & 87.4 & 11 & 31 \\
\hline \multirow[t]{9}{*}{ Narayan Gopal } & $9: 23-10: 26$ AM & 106.2 & 102.5 & & \\
\hline & $10: 26-11: 31 \mathrm{AM}$ & 99.3 & 95.7 & & \\
\hline & $11: 31 \mathrm{AM}-12: 31 \mathrm{PM}$ & 97.1 & 93.1 & & \\
\hline & 12:31-1:36 PM & 99.1 & 95.3 & & \\
\hline & 1:36-2:41 PM & 101.6 & 98.0 & & \\
\hline & 2:41-3:38 PM & 97.6 & 91.7 & & \\
\hline & 3:38-4:41 PM & 101.8 & 97.2 & & \\
\hline & 4:41- 5:49 PM & 102.4 & 97.8 & & \\
\hline & Total Day (Lavg) & 101.7 & 97.2 & 35 & 34 \\
\hline \multirow[t]{10}{*}{ Bhotahity } & $9: 12-10: 20$ AM & 98.2 & 91.7 & & \\
\hline & $10: 20-11: 17$ AM & 93.5 & 89.1 & & \\
\hline & 11:17 AM-12:17 PM & 87.8 & 79.9 & & \\
\hline & 12:17-1:20 PM & 83.2 & 75.8 & & \\
\hline & 1:20-2:18 PM & 90.9 & 87.2 & & \\
\hline & 2:18-3:26 PM & 92.1 & 88.1 & & \\
\hline & 3:26-4:27 PM & 94.4 & 91.3 & & \\
\hline & 4:27- 5:28 PM & 93.4 & 90.7 & & \\
\hline & 5:28-6:13 PM & 91.1 & 86.3 & & \\
\hline & Total Day (Lavg) & 93.3 & 88.2 & 17 & 38 \\
\hline
\end{tabular}

Noise remained above $90 \mathrm{dBA}$ over the entire period measured, although it decreased in the afternoon. A review of this data in Table 2 shows traffic police working at Narayan Gopal have significant noise exposure throughout the day.

The Bhotahity intersection is in the central city, where brick buildings in close proximity to the road reflect noise. Frequent horn use, in addition to the average vehicle density, contributes to noise intensity at this intersection. Average traffic density was 67 light vehicles and 5.7 heavy vehicles per minute. Data shows maximum noise of $98 \mathrm{dBA}$ from 9:00 and10:00 AM during rush hour traffic and relatively low noise levels in non-rush hours between 11:00 AM to 2: 00 PM. Personal noise data was collected from 9:15 AM to 6:15 PM.

Figure 2 is representative of a one hour plot of personal noise exposure. The dark gray line reflects the running Lavg for the OSHAHC, the black line reflects the running Lavg for the ACGIH value and the light gray line reflects the OSHANC running Lavg. The wide swings in the OSHANC show the noise level exceeded $90 \mathrm{dBA}$ for limited times each hour. Noise levels returned to values in the low to middle $70 \mathrm{dBA}$ between the short higher 


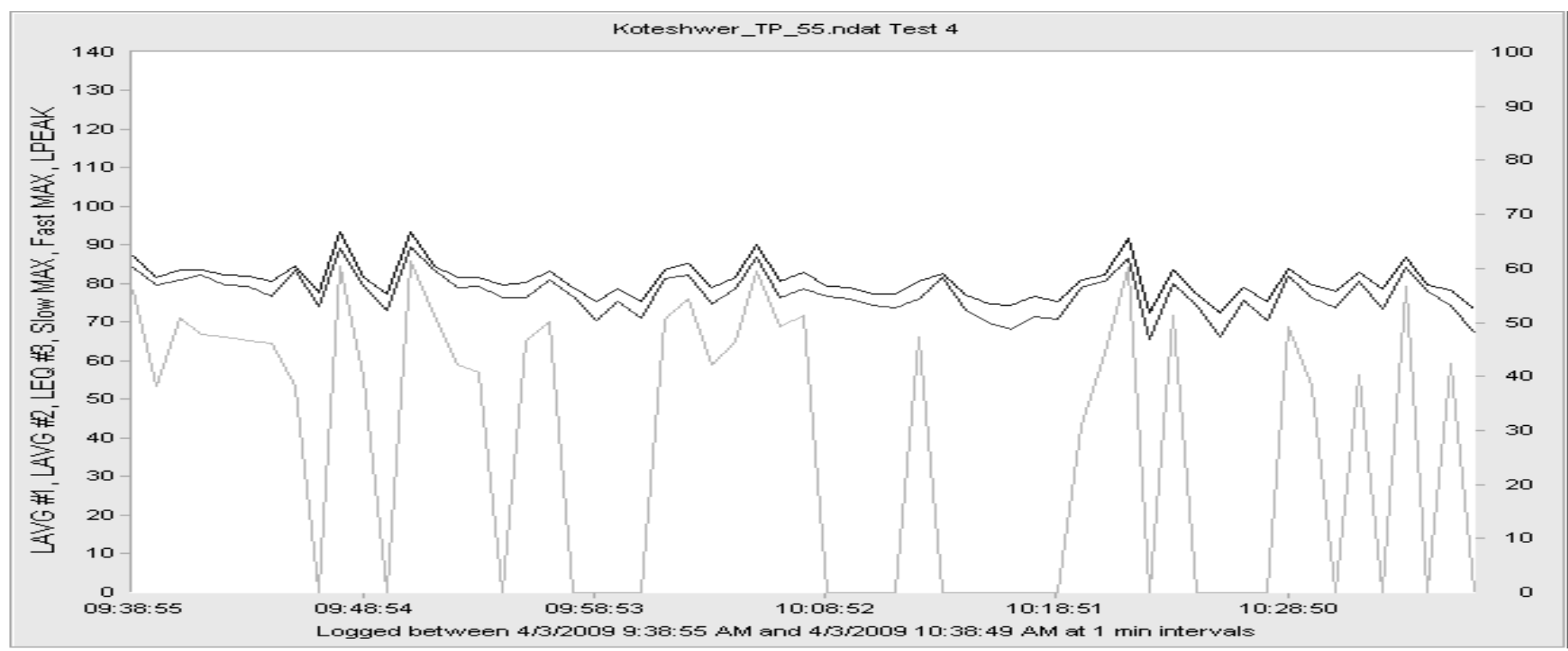

Figure 2. Typical one-hour time plot of personal sampling at Koteshwor Lavg for OSHAHC(gray), OSHANC(light gray) and ACGIH (black)

noise periods.

proximity to police, resulting in elevated noise exposure. It should be noted the ACGIH value, employing the $3 \mathrm{dBA}$ exchange rate, was consistently 6 to $8 \mathrm{dBA}$ higher than the OSHAHC value, employing the $5 \mathrm{dBA}$ exchange rate.

Figure 3 shows the full day measurements of the personal noise levels taken at Koteshwor.

We conducted a statistical analysis on the aggregated 52 personal samples employing a t-test. Analysis for this data shows a statistically significant $5.27 \mathrm{dBA}(\mathrm{Cl} 95 \% 2.60-7.95)$ higher noise level when using the $3 \mathrm{dBA}$ exchange rate compared to the 5 dBA exchange rate.

\section{Area Monitoring}

We conducted area monitoring at 5 intersections in an attempt to determine whether area samples would usefully enhance representative personal monitoring. In addition to Koteshwor, Narayan Gobal and Bhotahity, we sampled at Thapatali and Jawalakhel in the center of Kathmandu. At each intersection we collected multiple noise samples at different points within the intersection.

The dosimeter operated in the run mode for 1 hour during the day at each designated point. We collected area noise data in Koteshwor at 6 different points in the intersection representative of the traffic pattern. We collected area noise data in Narayan Gopal at 5 points in the intersection.

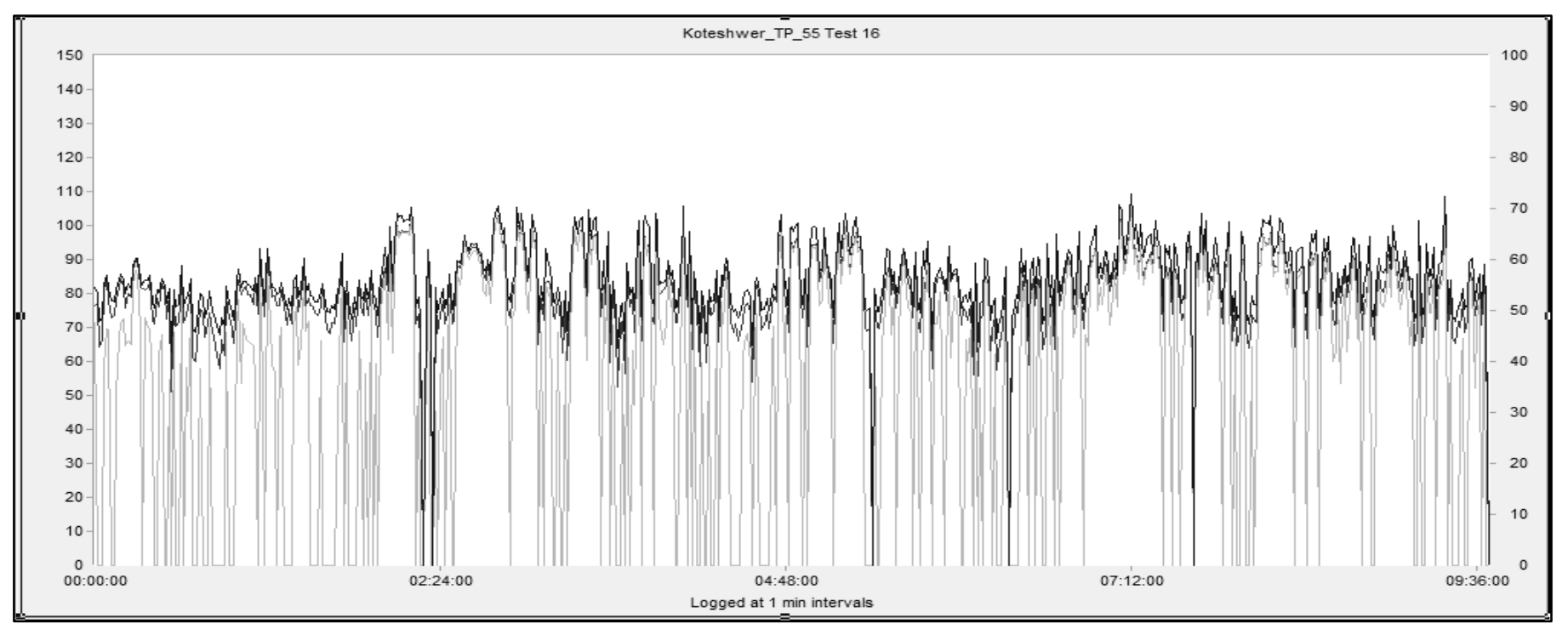

Figure 3. Full day personal sampling at Koteshwor Lavg for OSHAHC(gray), OSHANC(light gray) and ACGIH(black) 


\section{Original Article / IJOSH/ ISSN 2091-0878}

At Bhotahity we collected data at 4 points. At Thapathali, we collected data at 4 points which included the traffic kiosk. There is significant commercial and truck traffic at this major crossing of the Bagmati River. At Jawalakhel we collected data at 6 roundabout points along the crossroads and traffic kiosk. Considerable commercial and truck traffic pass through this intersection as well. This data is shown in Table III

In all we collected 48 area samples and conducted a statistical analysis on the aggregated samples employing a ttest. Analysis of this data shows a statistical difference of 6.73 dBA ( $\mathrm{Cl}$ 95\% 4.02-9.43) higher average value with the $3 \mathrm{dBA}$ exchange rate compared to the $5 \mathrm{dBA}$ exchange rate.

Table III - Area Monitoring

\begin{tabular}{|c|c|c|c|c|}
\hline $\begin{array}{l}\text { Traffic Chowk } \\
\text { Intersection }\end{array}$ & $\begin{array}{l}\text { Intersection } \\
\text { Point }\end{array}$ & Sampling Time (approximate times) & $\begin{array}{c}\text { TWA ACGIH } \\
(\mathrm{dBA})\end{array}$ & $\begin{array}{c}\text { TWA OSHA } \\
\text { (dBA) }\end{array}$ \\
\hline \multirow[t]{7}{*}{ Koteshwor } & Traffic Kiosk & 8:30-9:30 AM & 86.2 & 78.2 \\
\hline & Cross Road & 9:30-10:30 AM & 90.7 & 82.0 \\
\hline & & 10:30-11:30 AM & 86.0 & 81.9 \\
\hline & & $11: 30 \mathrm{AM}-12: 30 \mathrm{PM}$ & 82.5 & 78.2 \\
\hline & & 12:30-1:30 PM & 80.4 & 74.6 \\
\hline & Bus Stop & $1: 30-2: 30$ PM & 84.0 & 72.8 \\
\hline & Total Day (Lavg) & & 86.3 & 79.0 \\
\hline \multirow[t]{6}{*}{ Narayan Gopal } & Traffic Kiosk & 9:30-10:30 AM & 83.7 & 78.2 \\
\hline & Cross Road & 10:30-11:30 AM & 84.2 & 78.2 \\
\hline & & 11:30AM-12:30PM & 86.3 & 79.9 \\
\hline & & 1:30-2:30 PM & 81.3 & 76.5 \\
\hline & & 2:30-3:30 PM & 77.7 & 71.2 \\
\hline & Total Day (Lavg) & & 83.6 & 77.1 \\
\hline \multirow[t]{5}{*}{ Botahity } & Cross Road & 11:00AM-12:00PM & 79.2 & 70.2 \\
\hline & & 12:00-1:00 PM & 81.0 & 75.8 \\
\hline & & 1:00-2:00 PM & 78.5 & 72.2 \\
\hline & & 3:00- 4:00PM & 94.6 & 81.2 \\
\hline & Total Day (Lavg) & & 88.8 & 76.0 \\
\hline \multirow[t]{5}{*}{ Thapathali } & Cross Road & $9: 30-10: 30$ AM & 85.7 & 80.7 \\
\hline & & $10: 30-11: 30 \mathrm{AM}$ & 82.5 & 76.6 \\
\hline & & 11:30 AM-12:30 PM & 77.5 & 70.4 \\
\hline & & 2:30-3:30 PM & 80.8 & 75.2 \\
\hline & Total Day (Lavg) & & 82.6 & 76.5 \\
\hline \multirow[t]{7}{*}{ Jawalakhel } & Traffic Kiosk & 9:00-10:00 AM & 81.4 & 75.2 \\
\hline & Cross Road & 10:00-11:00 AM & 93.0 & 87.2 \\
\hline & & 11:00 AM-12:00PM & 96.3 & 88.8 \\
\hline & & 1:00-2:00 PM & 82.2 & 76.0 \\
\hline & & $2: 00-3: 00$ PM & 80.1 & 74.3 \\
\hline & & 3:00-4:00 PM & 81.5 & 74.3 \\
\hline & Total Day (Lavg) & & 90.6 & 82.3 \\
\hline
\end{tabular}

\section{Personal Samples Compared to Area Samples}

We then compared personal noise data to area noise data collected at the same intersections and times. Data in Table 2 and Table 3 shows the comparison in noise levels. An analysis, employing a standard t-test for each intersection showed the ACGIH personal measurements varied from $6.8 \mathrm{dBA}$ lower to 22.5 dBA higher, with an average difference of $11.55 \mathrm{dBA}(95 \% \mathrm{Cl}$ 9.46 - 13.64). This variation depends upon the positioning of the area monitor relative to the location of the traffic police wearing the personal monitor. The OSHAHC personal values varied from 2.1 dBA lower to $24.3 \mathrm{dBA}$ higher during these same time comparisons, with an average difference of $13.10 \mathrm{dBA}(95 \% \mathrm{Cl}$ 11.01-15.19). This data demonstrates the importance of collecting personal samples in order to accurately measure personal exposure. 


\section{Conclusion}

The average personal noise levels measured in this study ranged from 70 to $120 \mathrm{dBA}$. When using the $3 \mathrm{dBA}$ exchange rate personal sampling noise levels at each intersection ranged between 80-109 dBA for the following percentage of time: in Koteshwor $42 \%$ of the time, Bhotahity $55 \%$ of the time, and Narayan Gopal for $69 \%$ of the time. Traffic police are exposed to these sound levels for most of their duty hours. Therefore a hearing protection program has been recommended for all traffic police.

Where personal and area sampling were conducted simultaneously, the personal samples gave higher values than area samples. Based on these investigations, two sites where area sampling only was conducted merit additional investigation with personal monitoring.

\section{Recommendations}

The KMTPD study demonstrates that the current OSHA standard of $5 \mathrm{dBA}$ does not adquately protect workers against noise levels in the 85 to $90 \mathrm{dBA}$ range, particularly when there is frequent and rapid variation in noise levels. Under cirumstances where there is varying noise level it is important to employ an exchange rate of $3 \mathrm{dBA}$ to obtain accurate time average noise levels. These conditions exist in many workplace environments. The American Industrial Hygiene Association (AIHA) has encouraged OSHA to lower the exchange rate to $3 \mathrm{dBA}$ and the criterion level to $85 \mathrm{dBA}$ from the current standard. This data demonstrates the more prudent approach is to use the $3 \mathrm{dBA}$ exchange rate when evaluating personal exposure. Consideration should be given to employing the $3 \mathrm{dBA}$ exchange rate for all TWA measurements and the $85 \mathrm{dBA}$ criterion level for all Hearing Conservation programs. Additional studies concerning Noise Induced Permanent Threshold Shift calculations should be conducted using data employing the $3 \mathrm{dBA}$ exchange rate.

Area sampling alone cannot properly represent potential noise exposure. As observed in this study, the discrepancy between area samples and personal samples is likely to be more prevalent where there are wide fluctuations in the noise levels. Thus personal sampling is essential to comply with monitoring requirements and accurately determine when persons may be exposed to intermittent noise levels above 85 dBA TWA. Likewise when noise levels vary widely over relatively short period of time and distance, integrated sampling is recommended to accurately determine potential exposure.

\section{Acknowledgements}

This project was supported by the Fulbright United States Scholar program Award \#8507. The Nepal Health Research Council and the University of Findlay Institutional Review Boards approved this study. The cooperation of the Kathmandu Municipal Traffic Police Department and Dr. Sanjay Nath Khanal, from Kathmandu University, made this study possible.

\section{Reference}

1. Daniell, W. E., S. S. Swan, M. M. McDaniel, J. E. Cohen, and J. G. Stebbins, "Noise exposure and hearing loss prevention programmes after 20 years of regulations in the United States", Occupational and Environmental Medicine, 2006;63:343-351.

2. Dobie, Robert A., "Noise-Induced Permanent Threshold Shifts in the Occupational Noise and Hearing Survey: An Explanation for Elevated Risk Estimates," Ear \& Hearing, 2007, Vol. 28, No. 4, pages 580-591.

3. International Organization for Standardization (ISO), "Acoustics: Determination of Occupational Noise Exposure and Estimation of Noise-Induced Hearing Impairment", ISO1999, Geneva, 1990.

4. Joshi, S.K., Devkota, S., Chamling, S., Shrestha S., "Environmental noise induced hearing loss in Nepal", Kathmandu University Medical Journal (2003) Vol. 1, No. 3, 177183.

5. Khanal, G.K, Acharya, A., "Noise Pollution in Kathmandu Valley", a Report submitted to Youth in Environment, Nepal in technical co-operation with Landesdund fur Vogelschutz Lbv, Munich, Germany, 1994

6. Manandhar, M.S., Ranjitkar, N.G., Pradhan, P.K. and Khanal, N.R.; "Study on Health Hazard in Kathmandu City", Report submitted to National Committee for Man and the Biosphere, Kathmandu, 1987

7. National Institute of Occupational Safety and Health (NIOSH), "Criteria for a Recommended Standard: Occupational Noise Exposure" Publication No. 98-126, Washington 1998.

8. Occupational Safety and Health Agency (OSHA), "What constitutes an effective hearing conservation program?" available from www.osha.gov/dts/osta/otm/noise/hcp/index.html, June 2010.

9. Prince, Mary M., Leslie T. Stayner, Randall J. Smith, and Stephen J. Gilbert, "A re-examination of risk estimates from the $\mathrm{NIOSH}$ Occupational Noise and Hearing Survey (ONHS)," Education and Information Division, National Institute for Occupational Safety and Health, The Journal of the Acoustical Society of America, Volume 101, Issue 2, February 1997, pages $950-963$.

10.Suter, A "The Hearing Conservation Amendment: 25 years after", Noise \& Health, Jan-March 2009, Vol. 11, pages 2-7.

11.World Health Organization, Occupational and Community Noise, Information Fact Sheet No. 258, 2001, available from apps.who.int/inf-fs/en/fact258.html 